\title{
Cytologic Findings in Experimental in vivo Fallopian Tube Brush Specimens
}

\author{
Erika F. Rodriguez $^{\mathrm{a}}$ Deirdre Lum ${ }^{\mathrm{b}}$ Richard Guido ${ }^{\mathrm{b}}$ R. Marshall Austin ${ }^{\mathrm{a}}$ \\ Departments of a Pathology and ${ }^{\mathrm{b}}$ Obstetrics, Gynecology and Reproductive Sciences, University of Pittsburgh \\ Medical Center (UPMC), Magee-Womens Hospital, Pittsburgh, Pa., USA
}

\section{Key Words}

Brush cytology · Fallopian tube · Female genital tract ·

Hysteroscopy · Screening cytology · Serous carcinoma nition of the range of normal fallopian tube cytology should help to minimize false-positive interpretations of cytology specimens obtained in association with risk-reducing salpingo-oophorectomies.

(C) 2013 S. Karger AG, Basel

\begin{abstract}
Objective: The fallopian tube is now recognized as a primary source of precursor neoplastic lesions for pelvic serous adenocarcinomas. Cytologic features of fallopian tube brushings from low-risk patients have not been well described. Study Design: We describe the cytomorphology of tubal epithelium from prospectively collected experimental in vivo brushings from normal fallopian tubes of 7 low-risk patients. Liquid-based cytology slides and cell blocks were prepared and reviewed on all specimens. Results: Fifteen brush cytology specimens were obtained, ten by laparoscopy, four by hysteroscopy and one following hysterectomy and bilateral salpingo-oophorectomy on an ex vivo specimen. Variable cytologic features were documented for background, cellularity, cellular architecture, cilia, nuclear overlap, mitoses, nuclear pleomorphism, nuclear membrane changes and nucleoli. Negative P53 and Ki-67 stain results were documented in available cell blocks. Histopathologic salpingectomy findings and clinical follow-up were benign. Conclusion: Moderate nuclear pleomorphism and nuclear overlap, prominent single and multiple nucleoli and background granular debris were common challenging cytologic findings in fallopian tube brushings from low-risk patients. With experience, cellular changes can be recognized as benign. Recog-
\end{abstract}

\section{Introduction}

Ovarian cancer is regarded as one of the leading causes of cancer death among women, with nearly 21,990 new cases and 15,640 deaths reported in 2011 [1]. High-grade serous carcinoma is the most common cause of death attributed to ovarian epithelial malignancies. The majority of patients with high-grade serous pelvic carcinoma present with advanced stage disease, and approximately $70 \%$ of patients will die from disease progression despite aggressive surgical cytoreduction and chemotherapeutic regimens $[2,3]$.

A number of pelvic serous carcinomas initially appear to be extra-uterine/adnexal in origin with the ovaries normal or minimally involved, and such neoplasms have often been classified as primary peritoneal carcinomas $[4$, 5]. Primary serous adenocarcinoma of the fallopian tube has long been regarded as a very rare female genital tract neoplasm; however, in light of new criteria for the diagnosis of primary fallopian tube adenocarcinoma, it is now believed that many fallopian tube carcinomas have in the past been misclassified as ovarian or peritoneal carcinomas [6]. More recent understanding of the histopatho-

\section{KARGER}

E-Mail karger@karger.com

www.karger.com/acy (c) 2013 S. Karger AG, Basel

0001-5547/13/0576-0611\$38.00/0
Correspondence to: Prof. R. Marshall Austin

Department of Pathology, University of Pittsburgh Medical Center Magee-Womens Hospital, Room 4427

300 Halket Street, Pittsburgh, PA 15213 (USA)

E-Mail raustin@magee.edu 
logic, molecular and genetic alterations of pelvic serous neoplasms indicates that many of the tumors previously classified as high-grade serous carcinoma of the ovary or peritoneum have originated from the fimbriated epithelium of the fallopian tube [7-10]. Within this new paradigm, many now favor use of the new term pelvic serous carcinoma, defined broadly as tumors of serous histology arising in the ovary, fallopian tube or peritoneum [11].

There have been three main theories regarding the origin of pelvic serous carcinomas: (1) origin from ovarian surface epithelium or Mullerian inclusions; (2) origin from Mullerian epithelium elsewhere in the peritoneal cavity, and (3) origin from fallopian tube epithelium [12]. In recent years, after the association between tubal intraepithelial carcinoma and pelvic serous carcinoma was described, increasing attention has turned to the fallopian tube as the most likely site of origin $[7,8,13]$.

Several attempts to facilitate early detection of ovarian cancer have so far failed to develop a screening approach that is sensitive and specific enough for use in the general population [14]. With shifting of the carcinogenesis paradigm from an ovarian to a fallopian tube origin, several authorities have now suggested that the fallopian tube should be considered the primary focus of attention in screening efforts seeking to promote early detection of high-grade pelvic serous carcinomas [13].

Here we describe the cytomorphologic features of 15 brush cytology specimens obtained directly from the fallopian tube during a prospective study of a new fallopian tube brush sampling technique for possible future use in screening for high-grade pelvic serous carcinomas.

\section{Methods}

After approval by the University of Pittsburgh Institutional Review Board, patients were recruited from the Minimally Invasive Gynecologic Surgery Division at Magee-Womens Hospital of the University of Pittsburgh Medical Center. Medical records were reviewed for demographic, clinical and operative information.

\section{Inclusion Criteria}

Women aged 18-80 years undergoing laparoscopic total or subtotal (supracervical) hysterectomy with or without concurrent adnexal surgery were included in the study.

\section{Exclusion Criteria}

The following represents the exclusion criteria: history of prior tubal pathology or surgery including pelvic inflammatory disease, gonorrhea, chlamydia, tubal ectopic pregnancy and prior tubal ligation, history of gynecologic malignancy, BRCA1 or BRCA2 mutation, pregnancy, and history of endometrial ablation or uterus greater than $12.0 \mathrm{~cm}$.

\section{Method of Collection}

Samples were initially collected hysteroscopically, attempting to reach the fimbriated end of the fallopian tube; however, it was determined that the brush could reach only approximately $3.0 \mathrm{~cm}$ into the proximal end of each fallopian tube. Since the goal was to reach the fimbriated end of the fallopian tube, the surgical procedure protocol was modified and brushing of the fimbriated ends of the fallopian tubes was subsequently performed by laparoscopic introduction of the endoscopic cytology brushes into the fimbriated epithelium under direct laparoscopic visualization. A 3.2French brush was utilized for hysteroscopic sampling and a 5.0French brush for laparoscopic sampling. Both cytology brushes have a sterile protective sheath, allowing the brush to be retracted and protected while the catheter is introduced into the fallopian tube as well as after collection, thereby avoiding or limiting tissue contamination.

\section{Sampling Process}

The brush cytology specimens were submitted in ThinPrep Pap test vials. ThinPrep slides were prepared according to the manufacturer's specifications for PreservCyt samples using an automated processor (ThinPrep 3000, Hologic, Marlborough, Mass, USA). Staining of slides was performed on a Sakura Tissue-Tek Automated Slide Stainer (Sakura Finteck USA Inc., Torrance, Calif., USA). A cell block was prepared from residual ThinPrep Pap test vial fluid on all specimens. Hematoxylin and eosin (HE)-stained cell block slides were prepared. When the cell block slides contained appreciable fallopian tube epithelium, immunohistochemical stains for P53 protein (Ventana Medical System) and Ki-67 (Ventana Medical System) were also prepared. Companion histopathologic salpingectomy specimens were also reviewed for comparison, when available.

\section{Results}

\section{Patients}

Seven patients (median age 44 years, age range 39-69 years) were selected. A total of 15 specimens from 7 patients were submitted for cytologic examination. One of the patients had a specimen collected from only one fallopian tube. Another patient had 4 specimens collected, 2 by laparoscopy and 2 hysteroscopically. Cell blocks were prepared on all patient specimens; however, residual fallopian tube epithelial cells were identified in cell blocks of only 2 out of 7 patients ( 4 specimens). Three patients had histopathologic examinations of salpingectomy specimens, and in all three the histopathologic findings were benign and unremarkable. Clinical follow-up has been benign in all cases.

\section{Method of Collection}

Ten specimens were collected laparoscopically, four samples were collected hysteroscopically and one sample was collected after hysterosalpingo-oophorectomy. 
Table 1. Summary of cytomorphologic features

\begin{tabular}{lll}
\hline & Cellularity & \\
\cline { 2 - 3 } & moderate/high $(\mathrm{n}=13)$ & low $(\mathrm{n}=2)$ \\
\hline $\begin{array}{l}\text { Background } \\
\text { predominant })\end{array}$ & granular material $(\mathrm{n}=10)$ & $\begin{array}{l}\text { clean }(\mathrm{n}=4) ; \\
\text { blood }(\mathrm{n}=1)\end{array}$ \\
\hline Artifact & not significant $(\mathrm{n}=9)$ & crush $(\mathrm{n}=6)$ \\
\hline Architecture & clusters and single cells $(\mathrm{n}=11)$ & clusters $(\mathrm{n}=3)$ \\
\hline Cilia & present $(\mathrm{n}=15)$ & absent $(\mathrm{n}=0)$ \\
\hline Mitosis & absent $(\mathrm{n}=15)$ & present $(\mathrm{n}=0)$ \\
\hline
\end{tabular}

Table 2. Summary of nuclear features

\begin{tabular}{lll}
\hline & Anisonucleosis & \\
\cline { 2 - 3 } & moderate $(\mathrm{n}=13)$ & mild/none $(\mathrm{n}=2)$ \\
\hline Nuclear pleomorphism & moderate $(\mathrm{n}=13)$ & mild/none $(\mathrm{n}=2)$ \\
\hline Nucleoli & single nucleolus and multiple nucleoli $(\mathrm{n}=15)$ & predominantly inconspicuous nucleoli $(\mathrm{n}=0)$ \\
\hline Chromatin & mixed chromatin pattern $(\mathrm{n}=8)$ & predominantly hypochromatic $(\mathrm{n}=5) ;$ \\
Nuclear shape & mixture of shapes $(\mathrm{n}=14)$ & predominantly hyperchromatic $(\mathrm{n}=2)$
\end{tabular}

\section{Cellularity}

All specimens were judged as satisfactory for interpretation; however, two had low cellularity, both obtained from the same fallopian tube (one specimen obtained by hysteroscopy, the other by laparoscopy). The remainder of the specimens had moderate-to-high cellularity $(\mathrm{n}=13)$. Tables 1 and 2 summarize the cytomorphologic findings, and selected findings are illustrated in figures 1 and 2 .

\section{Background}

The background was clean in 4 samples. Ten samples had granular background material, two of which had associated red blood cells. One case had only red blood cells in an otherwise clean background.

\section{Artifact}

Moderate crush artifact was present in 6 specimens; four of them were obtained hysteroscopically and two laparoscopically. The remainder did not have significant crush artifact.

\section{Architecture}

The cells were distributed in clusters and single cells in 11 samples, two of which had an abundant single cell population. In three samples the cells were almost exclusively distributed in clusters. The clusters had moderate nuclear overlap in 14 specimens. Absent-to-mild nuclear overlap was noted in 1 case.

\section{Cytoplasmic Features}

On eight specimens columnar cytoplasmic configurations were identified. Columnar cell configurations were not evident on seven specimens. Cilia were easily identified in all cases.

\section{Nuclear Features}

Nuclear pleomorphism and anisonucleosis were moderate in 13 samples and mild in 2 samples. Nuclear membrane irregularities were mild in 9 samples and moderate in 6 . There was a mixture of round, oval and spindled nuclei in 9 samples, a mixture of round and oval nuclei in 3, round and spindled nuclei in 1, oval and spindle nuclei in 1, and in another sample nuclei were predominantly spindled. The majority of the samples had a mixed population of cells with single prominent nucleoli and multiple nucleoli. In 5 samples there was also a population of cells with inconspicuous nucleoli in addition to a population with single and multiple nucleoli. Nuclear grooves were easily identified in 11 samples. Nuclei had mixed chromatin features, both hyperchromatic 


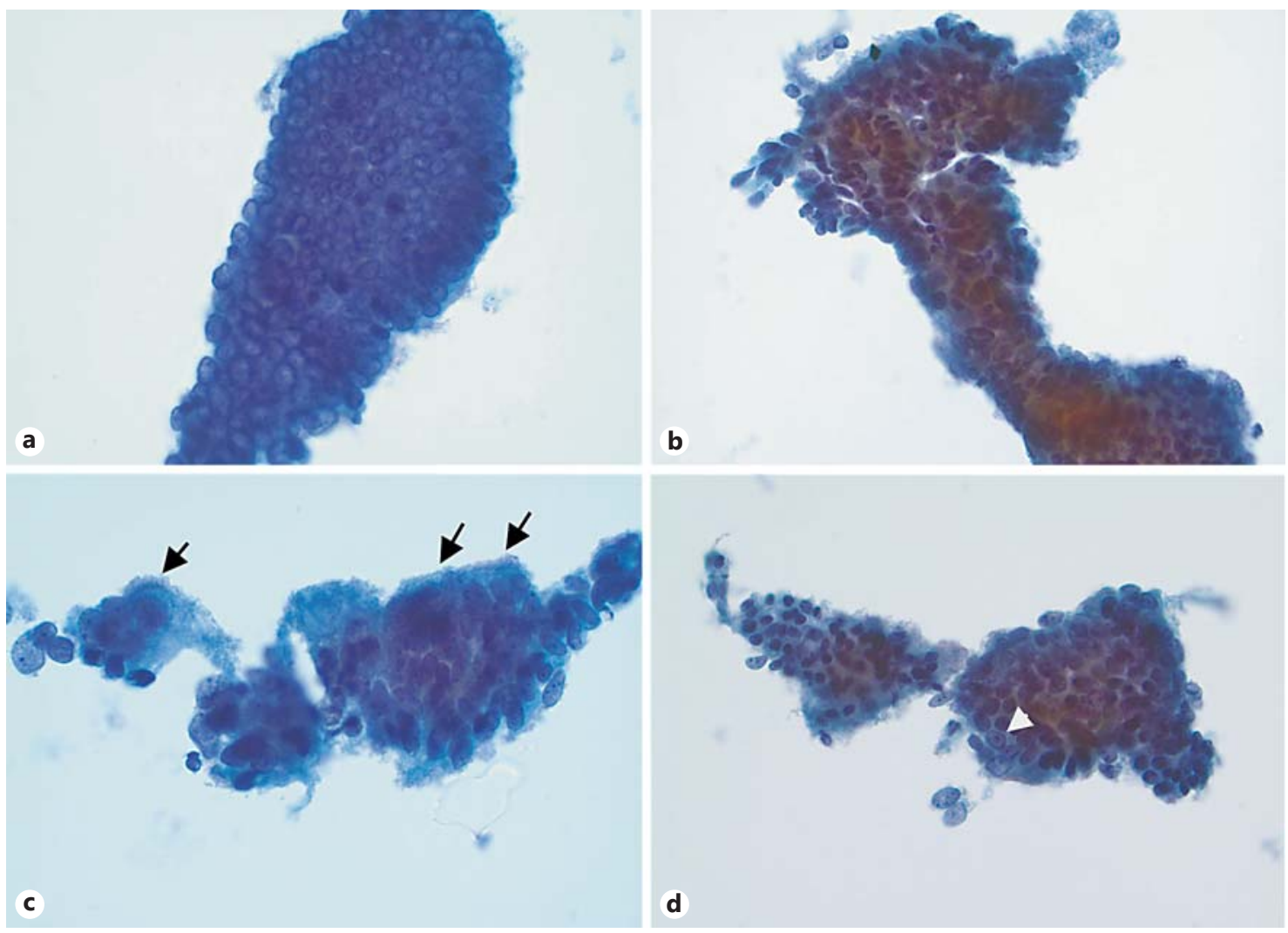

Fig. 1. a Cluster of epithelial cells forming a crowded honeycomb arrangement. The nuclei are variable in size. ThinPrep. $\times 40$. b Cluster of epithelial cells showing nuclear overlapping and pleomorphism. ThinPrep. $\times 40$. c Clusters of epithelial cells showing nuclear overlapping, pleomorphism and cilia at the periphery of the cluster (arrows). ThinPrep. $\times 40$. d Clusters of epithelial cells showing nuclear overlapping, pleomorphism, hyperchromasia, focal prominent nucleoli (white arrowhead) and cilia at the periphery of the cluster. ThinPrep. $\times 20$.

and hypochromatic, in 8 samples. Chromatin was predominantly hypochromatic in 5 samples and predominantly hyperchromatic in 2 samples. Table 2 shows a summary of nuclear features. Figure 3 illustrates nuclear features from selected samples.

\section{Presence of Mitotic Figures}

Mitoses were absent in all samples $(\mathrm{n}=15)$.

\section{Cell Block Immunocytochemical Studies}

Residual fallopian tube epithelial cells were identified in cell blocks in four specimens from 2 patients, two collected by laparoscopy and two hysteroscopically. The cell blocks had similar morphologic features as the cytology samples. There were no consistent differences in the cytologic features of the specimens collected by laparoscopy or hysteroscopy. Immunocytochemical studies for P53 and Ki-67 were negative on all four tested cell block samples.

\section{Cytologic Interpretations}

All cytologic preparations were interpreted as benign, although the presence of nuclear overlapping, crowding and nucleoli were initially regarded as benign atypia. With additional experience, these findings were increasingly recognized as within the spectrum of normal brush cytologic findings from the fallopian tube.

\section{Discussion}

In 1954, Papanicolaou [15] wrote regarding the exfoliative cytology of the fallopian tube: 'The cytology of desquamated epithelial cells of the fallopian tube is practically unknown.' Several decades later we are still challenged by limited documentation of the range of morphologic features of fallopian tube epithelium. 


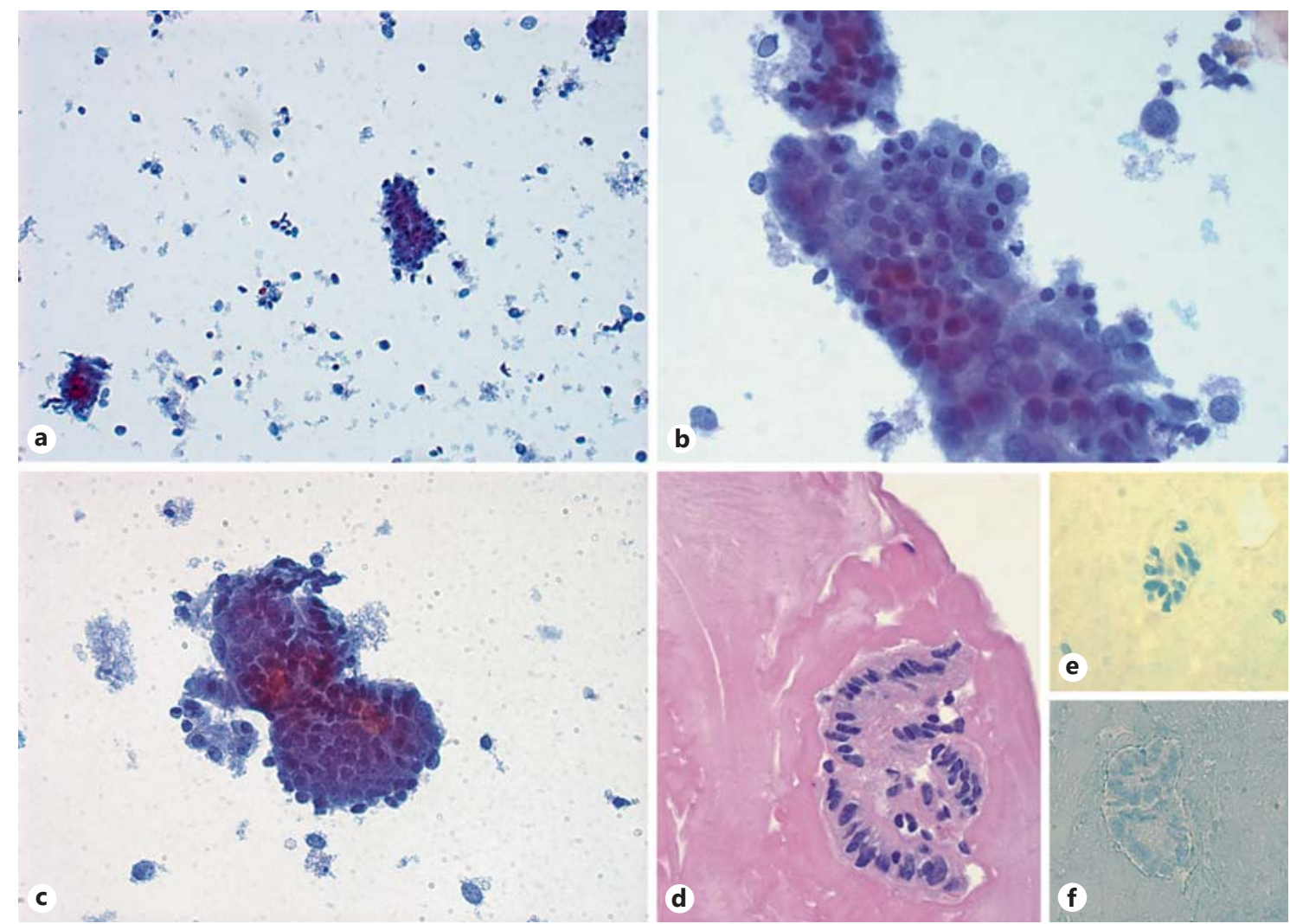

Fig. 2. Fallopian tube brush samples obtained from 1 representative patient. a Clusters of epithelial cells in a background of abundant single cells and granular material. ThinPrep. $\times 20$. b Crowded group of epithelial cells showing nuclear pleomorphism in a background of enlarged bare nuclei. ThinPrep. $\times 40$. c Crowded group of epithelial cells showing nuclear pleomorphism in a background of enlarged bare nuclei. ThinPrep. $\times 60$. d A cell block tubal epithelium sample. HE. $\times 40$. The clusters were negative for Ki-67 (e) and P53 (f) immunocytochemistry. $\times 40$.

Although cytopathologic specimens from the fallopian tube have not in the past been routinely obtained, the cytomorphologic features of epithelial cells of the fallopian tube obtained after salpingectomy by aspiration were described in some detail by Dudkiewicz $[16,17]$. The stated goal of that study was to describe the cytomorphology of the fallopian tube in order to better recognize the range of cytologic findings and to avoid misinterpretation of occasional fallopian tube cells found in routine Pap smears. As many as nine separate classes of cells and cellular material were put forward, and the author concluded that exfoliative cytology of the tubal epithelium is difficult and complex and further challenged by both menstrual cycle-associated variation and cellular degeneration. The main fallopian tube cell types described were: (1) cylindrical 'secretory cells' having large eccentric or central nuclei with 2-4 nucleoli and foamy granular cytoplasm; (2) 'ciliary cells' with cilia-covered apex and round-to-oval central nuclei with two to three nucleoli, and (3) 'peg cells', described as conical cells with very scant cytoplasm and dark, almost bare nuclei and one or two nucleoli. Another unusual and less common cell type described was that of 'cells of snakelike shape', elongated tadpole-like cells.

Cytologic scrape samples of the fallopian tube have also been described [18]. In these specimens, fallopian tube epithelial cells may be distributed in sheets, strips of cells, or as single cells. The sheets of cells may form honeycomb monolayer arrangements and the cells may overlap. The cells largely have the same polarity as seen in histologic samples. The ciliated cells commonly have a columnar configuration, a single round-to-oval nucleus, regular nuclear membranes and fine granular chromatin. Cilia are numerous and evenly spaced. The secretory cells also have a columnar shape and may contain small perinuclear vacuoles. Fallopian tube cells collected by this 


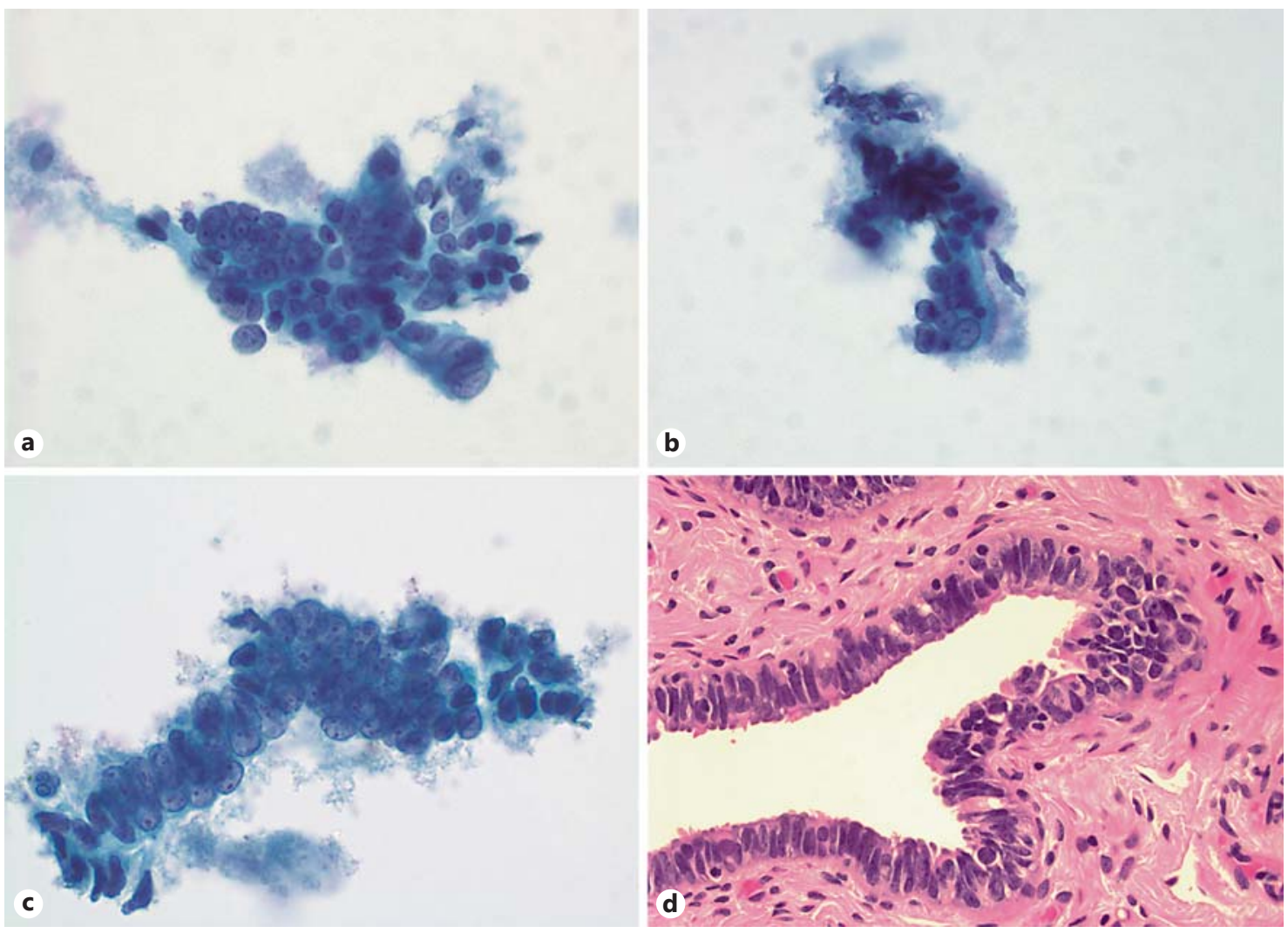

Fig. 3. Fallopian tube brush samples obtained from 1 representative patient. a Cluster of disorganized epithelial cells showing nuclear size variation and cilia at the periphery. ThinPrep. $\times 20$. b Loosely cohesive cluster of epithelial cells showing nuclear size variation, focal molding and prominent nucleoli. ThinPrep. $\times 40$. c Cluster of crowded pleomorphic cells with multiple nucleoli. ThinPrep. $\times 60$. d Histologic section of the fallopian tube showing cell overlapping, mild pleomorphism and cilia. HE. $\times 40$.

method are described as having evenly placed nuclei and only mild variation in size [18]. Touch imprint cytologic preparations from the fallopian tube have also been briefly described as a possible cost-effective alternative to routine histopathologic evaluation for laboratory confirmation of tubal sterilization specimens in developing countries [19]. Limited available published photomicrographs document clusters of fallopian tube epithelial cells as well as both ciliated and nonciliated small groups of columnar cells.

Although the diagnosis of fallopian tube carcinoma in cytology samples has been uncommon in the past, examples are well described in the literature. The first individual documented to have specifically suggested a diagnosis of fallopian tube carcinoma on a Pap smear was J. Ernst Ayre, inventor of the Ayre spatula [20]. The cells of fallopian tube carcinoma have been classically described as exfoliating in papillary clusters within a clean back- ground. The cells are of medium size, with high nuclearto-cytoplasmic ratios, irregular nuclei with abnormal chromatin and prominent nucleoli [20-22]. The cytoplasm is dense, but frequently vacuolated. Occult primary fallopian tube high-grade serous carcinoma has also been described based on pelvic washing cytology [23]. Cells are highly atypical with a high nuclear-to-cytoplasmic ratio, coarse chromatin and prominent nucleoli.

Cytologic sampling of the fallopian tube using brush techniques has previously been reported in the diagnosis of nonmalignant fallopian tube diseases associated with infertility. The fallopian tube cytobrush has been described as a useful tool for obtaining culture material to support diagnosis of Chlamydia salpingitis [24, 25]. Matsushima et al. [26] reported a wash method of fallopian tube cell collection to support cytologic diagnosis of endometriosis. None of these studies described the cytomorphologic features of brush cytology of background 
fallopian tube epithelium. Mulvany et al. [27] utilized a postsurgical tubal wash methodology to detect transtubal spread of malignant endometrial cells and concluded that positive tubal wash cytology samples can be detected in the presence of minimally invasive serous carcinoma, clear cell carcinoma and carcinosarcoma of the endometrium. Normal background fallopian tube cytology was not described.

In our current study, we describe cytologic findings in 15 fallopian tube brush cytology specimens from patients selected with no known risk factors for tubal pathology and no history of malignancy. The most challenging cytologic features were nuclear pleomorphism and presence of prominent nucleoli and multiple nucleoli in all cases. Prominent nucleoli and multiple nucleoli were described in Dudkiewicz's [16] studies of tubal cytology specimens immediately fixed in 95\% alcohol after aspiration from freshly resected salpingectomy specimens. Photomicrographs in these publications also show mildto-moderate nuclear size and shape variation, suggesting that these features may be best seen in specimens undergoing immediate wet fixation. These features appear less prominent in limited available published photomicrographs of scrape cytology specimens stained with Papanicolaou or Diff-Quik stains [18], or of Papanicolaoustained touch imprint specimens prepared from tubectomy and hysterectomy specimens [19]. The presence of single cells admixed with clusters was noted in 11 samples. The presence of single cells was also described in Dudkiewicz's aspiration samples [16], but not in scrape or touch imprint samples [18]. Although in scrape cytology specimens some nuclear overlap is noted in available photomicrographs, in our samples this finding was more pronounced in almost all cases. Another distinctive finding in our samples was the presence of granular cytoplasmic artifact in the majority of our samples, raising the cytologic differential of necrosis. We now believe these changes are the result of cytoplasmic rupture associated with the brushing procedure, since it can also be seen around bare nuclei and was especially abundant in the samples collected after salpingectomy, where the brushing was more vigorous.

The presence of easily identifiable cilia and the absence of mitotic figures in all our samples were reassuring features that supported a benign interpretation of the cellular changes, despite nuclear pleomorphism, nuclear overlap and granular background. The 'snake-like cells' described by Dudkiewicz were not seen in our samples. The samples were interpreted most often as atypical - favor benign reactive changes. As the study progressed, our in- creased familiarity with the cytomorphology of the samples, negative P53 and Ki-67 immunocytochemical findings on available cell block specimens, and comparison with available companion benign surgical pathology specimens led us to conclude that the described changes are part of the normal spectrum of fallopian tube epithelium obtained by our brush methodology with immediate fixation in liquid-based cytology vials.

Patients with BRCA1 or BRCA2 mutations undergoing risk-reducing salpingo-oophorectomies have been described with abnormal (atypical, suspicious and malignant) peritoneal cytology interpretations and normal tubal histopathology [28, 29]. Although follow-up of these cases is limited, the absence of any documented neoplastic recurrences should underscore the challenge of accurate cytologic interpretation. Similar challenges have been noted in the cytologic interpretation of endosalpingiosis in peritoneal washing specimens [30]. To the best of our knowledge, no reports to date document the cytomorphology of direct fallopian tube cytologic sampling of proposed precursor fallopian tube lesions, including tubal intraepithelial carcinoma, P53 signature, secretory outgrowths [31] or papillary tubal hyperplasia [32].

In this preliminary study of prospectively collected cytologic samples of the fallopian tube we describe cytologic characteristics that comprise a broad spectrum of benign cellular changes in the fallopian tube. To date, published descriptions of cytologic specimens obtained directly from the fallopian tube remain very limited. Such specimens are likely to become more common, given the new paradigm of serous carcinoma which focuses on the fallopian tube as the major anatomical site of origin [33]. It is important for cytopathologists who may become involved in the examination of these samples, specifically brush specimens, to gain experience and familiarity with the range of normal cytologic findings encountered in benign fallopian tube cytology specimens.

References

Siegel R, Naishadham D, Jemal A: Cancer statistics, 2012. CA Cancer J Clin 2012;62:10-29.

- 2 du Bois A, Herrstedt J, Hardy-Bessard AC, Muller HH, Harter P, Kristensen G, Joly F, Huober J, Avall-Lundqvist E, Weber B, Kurzeder C, Jelic S, Pujade-Lauraine E, Burges A, Pfisterer J, Gropp M, Staehle A, Wimberger P, Jackisch C, Sehouli J: Phase III trial of carboplatin plus paclitaxel with or without gemcitabine in first-line treatment of epithelial ovarian cancer. J Clin Oncol 2010;28:4162-4169. 
-3 Seidman JD, Horkayne-Szakaly I, Haiba M, Boice CR, Kurman RJ, Ronnett BM: The histologic type and stage distribution of ovarian carcinomas of surface epithelial origin. Int J Gynecol Pathol 2004;23:41-44.

-4 Jaaback KS, Ludeman L, Clayton NL, Hirschowitz L: Primary peritoneal carcinoma in a UK cancer center: comparison with advanced ovarian carcinoma over a 5 -year period. Int J Gynecol Cancer 2006;16(suppl 1):123-128.

5 Halperin R, Zehavi S, Langer R, Hadas E, Bukovsky I, Schneider D: Primary peritoneal serous papillary carcinoma: a new epidemiologic trend? A matched-case comparison with ovarian serous papillary cancer. Int J Gynecol Cancer 2001;11:403-408.

6 6 Zheng W, Fadare O: Fallopian tube as main source for ovarian and pelvic (non-endometrial) serous carcinomas. Int J Clin Exp Pathol 2012;5:182-186.

-7 Kindelberger DW, Lee Y, Miron A, Hirsch MS, Feltmate C, Medeiros F, Callahan MJ, Garner EO, Gordon RW, Birch C, Berkowitz RS, Muto MG, Crum CP: Intraepithelial carcinoma of the fimbria and pelvic serous carcinoma: evidence for a causal relationship. Am J Surg Pathol 2007;31:161-169.

-8 Carlson JW, Miron A, Jarboe EA, Parast MM, Hirsch MS, Lee Y, Muto MG, Kindelberger D, Crum CP: Serous tubal intraepithelial carcinoma: its potential role in primary peritoneal serous carcinoma and serous cancer prevention. J Clin Oncol 2008;26:4160-4165.

9 Crum CP, Drapkin R, Miron A, Ince TA, Muto M, Kindelberger DW, Lee Y: The distal fallopian tube: a new model for pelvic serous carcinogenesis. Curr Opin Obstet Gynecol 2007;19:3-9.

10 Kurman RJ, Shih Ie M: Molecular pathogenesis and extraovarian origin of epithelial ovarian cancer - shifting the paradigm. Hum Pathol 2011;42:918-931.

11 Levanon K, Crum C, Drapkin R: New insights into the pathogenesis of serous ovarian cancer and its clinical impact. J Clin Oncol 2008;26: 5284-5293.
Piek JM, Kenemans P, Verheijen RH: Intraperitoneal serous adenocarcinoma: a critical appraisal of three hypotheses on its cause. Am J Obstet Gynecol 2004;191:718-732.

13 Seidman JD, Zhao P, Yemelyanova A: 'Primary peritoneal' high-grade serous carcinoma is very likely metastatic from serous tubal intraepithelial carcinoma: assessing the new paradigm of ovarian and pelvic serous carcinogenesis and its implications for screening for ovarian cancer. Gynecol Oncol 2011;120: 470-473.

14 Fields MM, Chevlen E: Ovarian cancer screening: a look at the evidence. Clin J Oncol Nurs 2006;10:77-81.

15 Papanicolaou G: Exfoliative Cytology, ed 1. Cambridge, Harvard University Press, 1954.

16 Dudkiewicz J: Cytomorphology of epithelial cells of fallopian tubes obtained by aspiration from operative specimens. Am J Obstet Gynecol 1968;102:82-90.

17 Dudkiewicz J: Quantitative and qualitative changes of epithelial cells of fallopian tubes in women according to the phase of menstrual cycle: a cytologic study. Acta Cytol 1970;14: 531-537.

18 Herzberg AJ, Raso DS, Silverman JF: Color Atlas of Normal Cytology, ed 1. Philadelphia, Churchill Livingstone, 1999.

19 Aali BS, Malekpour R, Nakheii N, Mehdizadeh A: Utility and diagnostic accuracy of fallopian tube touch imprint cytology. Cytopathology 2005;16:252-255.

20 Fidler HK Lock DR: Carcinoma of the fallopian tube detected by cervical smear. Am J Obstet Gynecol 1954;67:1103-1111.

21 De May M: The Pap Test, ed 1. Singapore, ASCP, 2005.

-22 Safret A, Bosch B, Bannwart F, Rinderknecht B, Hafner HU: Carcinoma in situ of the fallopian tube presenting as a positive Pap smear. Acta Cytol 2004;48:462-464.

23 Jorns JM, Knoepp SM: Occult fallopian tube carcinoma detected in routine pelvic washing specimens submitted for staging: another justification for pelvic washing cytology? Diagn Cytopathol 2009;37:923-929.

-24 Cianci A, Palumbo G, Tempera G, Furneri PM: $C$ trachomatis detection in infertile women by using a tubal cytobrush during laparoscopy. Acta Eur Fertil 1989;20:363-365.
25 Haeusler G, Tempfer C, Lehner R, Sam C, Kainz C: Fallopian tissue sampling with a cytobrush during hysteroscopy: a new approach for detecting tubal infection. Fertil Steril 1997; 67:580-582.

26 Matsushima T, Kaseki H, Ishihara, K Araki T: Assessment of fallopian tube cytology for the diagnosis of endometriosis and hydrosalpinx. J Nippon Med Sch 2002;69:445-450.

27 Mulvany NJ, Arnstein M, Ostor AG: Fallopian tube cytology: a histocorrelative study of 150 washings. Diagn Cytopathol 1997;16: 483-488.

28 Landon G, Stewart J, Deavers M, Lu K, Sneige $\mathrm{N}$ : Peritoneal washing cytology in patients with BRCA1 or BRCA2 mutations undergoing risk-reducing salpingo-oophorectomies: a 10-year experience and reappraisal of its clinical utility. Gynecol Oncol 2012;125:683686.

29 Manchanda R, Drapkin R, Jacobs I, Menon U: The role of peritoneal cytology at risk-reducing salpingo-oophorectomy (RRSO) in women at increased risk of familial ovarian/tubal cancer. Gynecol Oncol 2012;124:185-191.

30 Sneige N, Dawlett MA, Kologinczak TL, Guo $\mathrm{M}$ : Endosalpingiosis in peritoneal washings in women with benign gynecologic conditions. Cancer Cytopathol 2013, E-pub ahead of print.

31 Crum CP, McKeon FD, Xian W: The oviduct and ovarian cancer: causality, clinical implications, and 'targeted prevention'. Clin Obstet Gynecol 2012;55:24-35.

32 Kurman RJ, Vang R, Junge J, Hannibal CG, Kjaer SK, Shih Ie M: Papillary tubal hyperplasia: the putative precursor of ovarian atypical proliferative (borderline) serous tumors, noninvasive implants, and endosalpingiosis. Am J Surg Pathol 2011;35:1605-1614.

-33 Rungruang B, Hood BL, Sun M, Hoskins E, Conrads TP, Zorn KK: Novel surgical approaches for sampling the ovarian surface epithelium and proximal fluid proteome. J Proteome Res 2010;9:6071-6076. 